\title{
A decade of experience in prescribing hydroxychloroquine and azithromycin: A retrospective analysis of medication queries in a Saudi drug and poison information center
}

\author{
Abdullah U Althemery ${ }^{1 *}$, Amal Hassan AL-Najjar ${ }^{2}$, Mesfer S Almalki², Abdullah \\ A Alfaifi ${ }^{1}$, Nehad J Ahmed ${ }^{1}$ \\ ${ }^{1}$ Department of Clinical Pharmacy, College of Pharmacy, Prince Sattam bin Abdulaziz University, Al-Kharj 11942, ${ }^{2}$ Drug and \\ Poison Information Specialist, Pharmacy Services, Security Forces Hospital Program, Riyadh 11481, Saudi Arabia \\ *For correspondence: Email: a.althemery@psau.edu.sa; Tel: +96611 5886051
}

Sent for review: 12 January 2021

Revised accepted: 24 April 2021

\begin{abstract}
Purpose: To analyze drug information queries related to treatment with hydroxychloroquine (HCQ), chloroquine (CQ), and azithromycin submitted to a local drug and poison information center in Riyadh, Saudi Arabia.

Methods: This retrospective study explored HCQ-, CQ-, and azithromycin-related inquiries submitted to the Drug and Poison Information Center at the Security Forces Hospital Program, Riyadh, Saudi Arabia. These inquiries were analyzed quantitatively and qualitatively. The quantitative analysis included the frequency of each request per year, the profession of the requesters, and the source material classification. A thematic analysis was also performed to categorize requests from healthcare professionals.

Results: The Drug and Poison Information Center received 10,685 usable inquiries between 2005 and 2018. There were 160 CQ-, HCQ-, and azithromycin-related queries. Most requests were made by pharmacists $(61.25 \%)$. The main sources used to answer the queries were tertiary (92.31 \%) and primary (7.69\%) sources. In the dataset, three major topics were identified: administration and dosing, safety, and pregnancy and lactation, each associated with a query subset.

Conclusion: These results emphasize the importance of continued education on antimicrobial agents in general, and HCQ, CQ, and azithromycin in particular. The three items have been identified as focus areas that policymakers can us to ensure the quality of future medication prescriptions.
\end{abstract}

Keywords: Hydroxychloroquine, Chloroquine, Azithromycin, COVID-19 treatment, Drug information queries, Antimicrobial agent

\begin{abstract}
This is an Open Access article that uses a fund-ing model which does not charge readers or their institutions for access and distributed under the terms of the Creative Commons Attribution License (http://creativecommons.org/licenses/by/4.0) and the Budapest Open Access Initiative (http://www.budapestopenaccessinitiative.org/read), which permit unrestricted use, distribution, and reproduction in any medium, provided the original work is properly credited.
\end{abstract}

Tropical Journal of Pharmaceutical Research is indexed by Science Citation Index (SciSearch), Scopus, International Pharmaceutical Abstract, Chemical Abstracts, Embase, Index Copernicus, EBSCO, African Index Medicus, JournalSeek, Journal Citation Reports/Science Edition, Directory of Open Access Journals (DOAJ), African Journal Online, Bioline International, Open-J-Gate and Pharmacy Abstracts

\section{INTRODUCTION}

The outbreak of the coronavirus disease 2019 (COVID-19) originated in Wuhan, China, from where it quickly spread globally [1]. Most patients with COVID-19 are either asymptomatic or present with mild symptoms including fever, cough, and fatigue. In some patients, however, it causes progressive respiratory failure and massive alveolar damage that can be fatal, 
especially in people with underlying conditions, elderly patients, and immunocompromised patients [1]. To date, there is no specific treatment for COVID-19, but medications initially developed to treat other viral infections are now being tested for efficacy against SARS-CoV-2, the virus that causes COVID-19 [1]. Several studies have found that hydroxychloroquine (HCQ) and chloroquine (CQ) inhibit angiotensinconverting enzyme-2 glycosylation and significantly reduce the infection of host cells by SARS-CoV-2 in vitro [2]. Moreover, the results of a study by Gautret et al suggested that the combination of $\mathrm{HCQ}$ and azithromycin exerts a synergistic effect [3].

Both $C Q$ and $H C Q$ have been approved by the US Food and Drug Administration (FDA) for the prevention and treatment of malaria [4]. HCQ has also been approved by the US FDA for use in systemic lupus erythematosus and rheumatoid arthritis [4]. Both medications have excellent oral absorption and bioavailability with a long half-life, which only requires infrequent dosing to prevent and treat malaria [4]. Moreover, both treatments are reportedly inexpensive, widely available, safe, and their side effects are commonly mild and transient [4].

Azithromycin acts as a broad-spectrum antibiotic with bacteriostatic activity and forms part of a subclass of macrolide antibiotics known as azalides. Its activity spectrum includes the Mycobacterium avium complex, Treponema pallidum, Mycoplasma pneumoniae, and Chlamydia species [5]. Azithromycin is effective against the Zika and Ebola viruses in vitro [6], and prevents serious respiratory tract infections when administered to patients suffering from viral infections [5].

The role of drug information centers in healthcare settings has increased greatly due to the high influx of pharmaceutical molecules that pose serious challenges to healthcare professionals. Pharmacists play a critical role in promoting appropriate drug use by providing reliable and useful information on drugs, ultimately leading to better patient outcomes. Drug information request electronic forms are commonly used to document drug queries from healthcare professionals [7]. These queries can also be used to identify areas of limited knowledge among healthcare professionals.

The objective of this study was to analyze drug information queries related to $\mathrm{HCQ}, \mathrm{CQ}$, and azithromycin treatments that were submitted to a local drug and poison information center (DPIC) between 2005 and 2018 and provide updated information regarding these queries.

\section{METHODS}

This retrospective study included all inquiries submitted between January 1, 2005 and December 31, 2018 to the Drug \& Poison Information Center (DPIC) at the Security Forces Hospital Program, Riyadh, Saudi Arabia, which is a tertiary care facility with over 500 beds that delivers healthcare to the Ministry of Interior employees and their families. Institutional Review Board (IRB) approval was obtained from the research committee of the Security Forces Hospital Program (approval no. 19-357-55).

All inquiries received at the DPIC which mentioned $\mathrm{HCQ}, \mathrm{CQ}$, and azithromycin were assessed for brand names associated with each treatment. Local brand names were examined using the Saudi Food and Drug Authority website, specifically the portal for drugs registered in Saudi Arabia. International brand names were verified using Drugdex [8].

Each inquiry was analyzed quantitatively and qualitatively. The quantitative analysis included the frequency of each request year, profession of the requester, and classification of the assessed reference. The request years were divided into two periods: 2005-2012 and 2013-2018. The cutoff year 2013 was chosen due to the inauguration of a nationwide DPIC that serves all healthcare institutions and the public [9]. The references were classified as either primary or tertiary sources. Primary sources included the most recent information available, such as randomized clinical trials and other journal articles, except for review articles [10]. Tertiary sources were all types of materials that summarized or condensed the primary materials. Tertiary sources included books, pharmacy electronic databases, review articles, and compendia [10]. The type of profession providing the answers was classified as a pharmacist versus other healthcare professionals. Statistical analyses were performed using the R StudioIntegrated Development Environment software.

\section{Data analysis}

The inquiries were qualitatively analyzed using a thematic analysis method. This method was defined as a technique focused on the interpretation of qualitative information patterns that should be identified and analyzed by researchers [11]. As part of the analysis process, two researchers independently coded the topics of each inquiry. Ultimately, these topics were 
classified as: therapeutics and safety, identification, administration and dosage, availability and supply, side effects and interactions, and pregnancy and lactation. Inquiries pertaining to topical use were excluded from the analysis due to their incompatibility with the study objective.

\section{RESULTS}

The assessment of the inquiries submitted to the DPIC between 2005 and 2018 identified 10,685 usable queries (Figure 1). Further screening identified 160 inquiries related to $\mathrm{CQ}$ or $\mathrm{HCQ}(15$ $\%$ ) and azithromycin (85\%). Approximately $60 \%$ of these inquiries were received before 2010 (85 questions), and $40 \%$ were received during or after 2013 (58 questions). Most queries were submitted by pharmacists, who accounted for $61.25 \%$ of the inquiries received by the DPIC, whereas $38.75 \%$ contributed by other healthcare professionals; $34.27 \%$ physicians, and $4.48 \%$ nurses. Moreover, the majority of queries were asked by healthcare professionals associated with the hospital. Tertiary sources were used to address $92.31 \%$ of the questions, and primary sources were consulted to answer the remaining questions $(7.69 \%)$. The main tertiary source of information was Drugdex (85.61\%).

Three major categories, each associated with a subset of queries, were derived from the dataset (Table 1). One category focused on the aspects of pregnancy $(7.7 \%)$ and lactation $(1.41 \%)$ when using any of the studied medications. The administration and dosage category represented an essential part of the queries (50\%), which covered a range of topics related to specific diseases such as pneumonia or systemic lupus

Over 19,000 inquiries were scanned using hard and soft copies from 2005-2018

\begin{tabular}{|c|}
\hline 10,685 inquiries remained after removal of duplicates and unreadable inquiries \\
\hline 160 inquiries were identified related to hydroxychloroquine, chloroquine, and azithromycin \\
\hline 136 inquiries related to azithromycin \\
\hline \\
\hline \\
\hline 143 inquiries remained after deleting questions related to topical use of the treatment \\
\hline 128 inquiries related to azithromycin \\
\hline
\end{tabular}

Figure 1: Flowchart of extracting inquiries related to hydroxychloroquine, chloroquine, and azithromycin

Table 1: Samples of drug-related inquiries submitted to the DPIC between 2005 and 2018

\begin{tabular}{|c|c|}
\hline Question & Category \\
\hline $\begin{array}{l}\text { - "Can hydroxychloroquine be given to a pregnant female?" } \\
\text { - "Can hydroxychloroquine be given } 200 \text { mg bid?" } \\
\text { - "Can we prescribe azithromycin for } 6 \text { days in pneumonia?" } \\
\text { - "Does cyclosporine or azithromycin or doxycycline cause an increase in } \\
\text { - } \quad \text { "I have a pregnant patient; can I give her azithromycin?" } \\
\text { - "Is it safe to administer carbimazole \& azithromycin?" } \\
\text { - "What is the dose of hydroxychloroquine for systemic lupus } \\
\text { - "Wrythematosus?" } \\
\text { - "Can I combine azithromycin with cefuroxime for a patient with } \\
\quad \text { pneumonia?" }\end{array}$ & $\begin{array}{l}\text { Pregnancy } \\
\text { Administration \& Dosage } \\
\text { Administration \& Dosage } \\
\text { Safety } \\
\text { Pregnancy } \\
\text { Safety } \\
\text { Administration \& Dosage } \\
\text { Safety } \\
\text { Safety }\end{array}$ \\
\hline
\end{tabular}


erythematosus. Some queries in the administration and dosage categories covered issues related to the dosing of either $\mathrm{HCQ}$ or azithromycin. Several queries were assigned under the safety category: interaction (11.7\%), side effects $(4.93 \%)$, and overdose $(2.11 \%)$. The respective requests were focused on the two medications in relation to drug-drug interactions or drug-disease interactions.

Queries about azithromycin administration and dosing were mainly related to the dose for treating acne vulgaris and lower respiratory tract infections. Medication safety queries have focused on gastrointestinal side effects. Queries related to the safety of $\mathrm{HCQ}$ focused on vision problems.

\section{DISCUSSION}

This study analyzed drug information queries related to $\mathrm{HCQ}, C Q$, and azithromycin, which resulted in an assessment of healthcare professionals' knowledge of the targeted treatment options. The quantitative analysis showed that the majority of the questions were answered using tertiary sources; thus, these questions can be classified as background information [10]. Indeed, HCQ and $C Q$ have narrow indications, and it is expected that these treatments would be associated with limited knowledge from clinicians [4].

The results revealed that a higher proportion of requests were received before 2010 . This could be attributed to two factors. First, $\mathrm{HCQ}$ was initially approved for malaria, and the number of cases has declined over the years [4]. Second, the Saudi Ministry of Health activated a unique national number that unified many public service tasks, including answering questions related to drugs and poisoning [9]. These two developments could explain the decreasing number of queries related to the assessed treatment options between 2005 and 2018 .

Our qualitative analysis identified the major question topics that we assigned as administration and dosage, safety, and pregnancy and lactation. Queries about azithromycin administration and dosing were mainly related to the dose for treating acne vulgaris and lower respiratory tract infections. The adult dose for mild-to-moderate, communityacquired pneumonia is as follows: $500 \mathrm{mg}$ tablet orally on the first day, then $250 \mathrm{mg}$ each day from the second to the fifth day or one single dose of $2 \mathrm{~g}$ of extended-release suspension or $500 \mathrm{mg}$ intravenously each day for a minimum of two days, then an oral dose of $500 \mathrm{mg}$ each day until the end of the treatment course ( 7 to 10 days). For patients aged 6 months or older, the recommended first dose would be $10 \mathrm{mg} / \mathrm{kg}$, but not exceeding $500 \mathrm{mg}$ per dose orally either as a tablet or immediate-release suspension. The recommended second to the fifth day dose is 5 $\mathrm{mg} / \mathrm{kg}$ but does not exceed $250 \mathrm{mg}$ per dose; this dose is also recommended for outpatient treatment in children older than 3 months. For patients aged 6 months or older, who have a bodyweight of less than $34 \mathrm{~kg}$, a single $60 \mathrm{mg} / \mathrm{kg}$ oral dose of extended-release suspension is recommended whereas for those with a body weight of $34 \mathrm{~kg}$ or more, a single $2 \mathrm{~g}$ oral dose for inpatient treatment is recommended. If older than 3 months, $10 \mathrm{mg} / \mathrm{kg}$ intravenously daily is recommended for at least 2 days, then increases by $5 \mathrm{mg} / \mathrm{kg}$ orally once daily to complete the treatment course. Azithromycin is not indicated for the treatment of Acne vulgaris [12].

The queries on administration and dosing of $\mathrm{HCQ}$ were mainly related to the dose for treating systemic lupus erythematosus. The adult dose for the treatment of lupus erythematosus is $200-$ $400 \mathrm{mg}$ orally once daily or equally divided twice daily, with a maximum dose of $400 \mathrm{mg} / \mathrm{day}$. It is not recommended to treat lupus erythematosus in pediatric patients [12].

Medication safety queries were related to adverse effects and drug-drug interactions. The common adverse effects of azithromycin are injection site reaction, abdominal pain, diarrhea, flatulence, nausea, vomiting, increased liver enzymes, headache, and abnormal vision [12]. There are several contraindicated major and moderate drug-drug interactions, including those with cisapride, ergotamine, and sparfloxacin. Moreover, there are major interactions between warfarin and clarithromycin, as well as moderate interactions with atorvastatin in addition to many other interactions [26]. Benn et al. reported that headaches, gastrointestinal upset, and dizziness are common adverse effects of azithromycin. In addition, malignant arrhythmias and prolongation of the rate-corrected electrocardiographic QT (QTc) interval have been reported [13].

HCQ has been associted with several serious adverse effects, such as torsade de pointes, hypoglycemia, agranulocytosis, aplastic anemia, thrombocytopenia, muscle disorders, retinal disorders, hearing loss, and angioedema. Approximately $7.5 \%$ of the patients had retinal disorders [12]. The major risk factors for $\mathrm{HCQ}$ are its interactions with many other drugs. $\mathrm{HCQ}$ co-administration with most of these drugs is contraindicated, including cisapride and sparfloxacin, as well as amiodarone and 
moxifloxacin. Shipman et al. stated that the use of $\mathrm{HCQ}$ for cutaneous lupus erythematosus is effective at a dose of $400 \mathrm{mg} / \mathrm{day}$, with an extremely low incidence of adverse effects, such as retinopathy [14].

Both azithromycin and $\mathrm{HCQ}$ have a known risk of QTC prolongation leading to torsade de pointes with an approximate rate of $200-250 \mathrm{bpm}$ and an irregular rhythm without $P y$ wave and $P R$ interval. Since the new regimen recommends using the HCQ-azithromycin combination for COVID-19 treatment, the risk score for predicting QTC interval prolongation should be performed for the patient before treatment initiation. Moreover, it will be essential during treatment to perform EKG monitoring, avoid any other medication that could affect QTc, and correct potential electrolyte imbalance [12].

Fetal risk cannot be ruled out when using azithromycin during pregnancy and lactation. The U.S. FDA pregnancy category $B$ indicates that they lack strong evidence in pregnant women, and animal studies have failed to demonstrate a risk to the fetus [12]. Furthermore, there is a potential risk for infants during lactation [12]. Specifically, azithromycin is secreted into human milk and should be used only if needed. According to Sarkar et al., pregnant women exposed to azithromycin did not show an increase in the incidence of major malformations above the baseline of $1 \%-3 \%$, and macrolide antibiotics are generally safe during pregnancy [15].

For the use of HCQ in pregnancy and lactation, Australia's Therapeutic Goods Administration has assigned pregnancy category $D$, but there is no assigned U.S. FDA pregnancy category. Thus, the use of $\mathrm{HCQ}$ should be avoided during pregnancy, except for malaria therapy. This drug passes through the placenta, however, infant risk is minimal [12]. Numerous studies have shown that patients with lupus erythematosus, who continued HCQ during pregnancy, had diminished flares and improved pregnancy outcomes, including longer fetal gestation and higher birth weight of infants [16]. Encouragingly, Flint et al reported that antimalarial drugs are compatible with pregnancy, without any sign of safety alarms, and that several professional society guidelines recommend continuing $\mathrm{HCQ}$ during pregnancy [17]. Moreover, in support of this approach, a survey among North American rheumatologists showed that more than $69 \%$ of the rheumatologists continued providing $\mathrm{HCQ}$ prescriptions for their pregnant patients [18].

\section{Limitations of the study}

This study highlights areas where continuous education is needed with regard to therapeutic treatments. However, it is important to emphasize that the purpose of this study was not to reach conclusions regarding the appropriateness of using $\mathrm{HCQ}, \mathrm{CQ}$, and azithromycin for patients with COVID-19. The strongest evidence of clinical information can be obtained from meta-analyses and randomized clinical trials [10]. Moreover, the information obtained in this study was based on a single center, and future research could validate similar methodologies in different centers.

\section{CONCLUSION}

Findings from this retrospective study emphasize the importance of continued education about antimicrobial agents in general, and specifically about $\mathrm{HCQ}, \mathrm{CQ}$, and azithromycin. The three items can be used by policymakers as focus areas to ensure the quality of future medication prescriptions.

\section{DECLARATIONS}

\section{Acknowledgement}

This project was supported by the Deanship of Scientific Research at Prince Sattam bin Abdulaziz University through research proposal no. 2017/03/8275. In addition, the Security Force Hospital Program in Riyadh is acknowledged for administrative support.

\section{Conflicts of interest}

No conflict of interest is associated with this work.

\section{Contribution of authors}

The authors declare that this study was done by the authors named in this article and that all liabilities pertaining to claims relating to the content of this article will be borne by them. Althemery supervised the work, designed the conceptual framework, took part in the methodology, and funds allocation. Alnajjar was responsible for data curation and methodology. Almalki worked on data acquisition and investigation. Alfaifi validated the methodological process and participated in writing the manuscript. Nehad contributed to writing, reviewing, and editing of the manuscript. The manuscript was comprehensively read and approved for publication by all authors.

Trop J Pharm Res, May 2021; 20(5): 1053 


\section{Open Access}

This is an Open Access article that uses a funding model which does not charge readers or their institutions for access and distributed under the terms of the Creative Commons Attribution License (http://creativecommons.org/licenses/by/ 4.0) and the Budapest Open Access Initiative (http://www.budapestopenaccessinitiative.org/rea d), which permit unrestricted use, distribution, and reproduction in any medium, provided the original work is properly credited.

\section{REFERENCES}

1. Cascella M, Rajnik M, Cuomo A, Dulebohn SC, Di Napoli R. Features, Evaluation and Treatment Coronavirus (COVID-19). Treasure Island (FL): StatPearls Publishing; 2020 [cited 2020 Dec 1]. Available from: http://www.ncbi.nlm.nih.gov/pubmed/32150360

2. Wang M, Cao R, Zhang L, Yang X, Liu J, Xu M, Shi Z, Hu $Z$, Zhong $W$, Xiao G. Remdesivir and chloroquine effectively inhibit the recently emerged novel coronavirus (2019-nCoV) in vitro. Cell Res 2020; 30(3): 269-271. Available from: http://www.ncbi.nlm.nih.gov/ pubmed/32020029

3. Gautret $P$, Lagier JC, Parola P, Hoang VT, Meddeb L, Mailhe $M$, Doudier B, Courjon J, Giordanengo V, Vieira $V E$, et al. Hydroxychloroquine and azithromycin as a treatment of COVID-19: results of an open-label nonrandomized clinical trial. Int J Antimicrob Agents 2020; 56(1): 105949. doi: 10.1016/j.ijantimicag.2020.105949.

4. Yazdany J, Alfred HJ. Use of hydroxychloroquine and chloroquine during the COVID-19 pandemic: what every clinician should know. Ann Intern Med 2020; 172(11): 754-755. doi: 10.7326/M20-1334

5. Sandman Z, Iqbal OA. StatPearls: Azithromycin. Treasure Island (FL): StatPearls Publishing; 2020 [cited 2020 Dec 1] https://www.ncbi.nlm.nih.gov/books/ NBK557766/

6. Bosseboeuf E, Aubry M, Nhan T, de Pina JJ, Rolain JM, Raoult D, Musso D. Azithromycin Inhibits the Replication of Zika Virus. J Antivir Antiretrovir 2018; 10(1): 6-11. doi: 10.4172/1948-5964.1000173.
7. Almazrou DA, Ali S, Alzhrani JA. Assessment of Queries Received by the Drug Information Center at King Saud Medical City. J Pharm Bioallied Sci 2017; 9(4): 246-250.

8. The Saudi Food and Drug Authority (SFDA). Registered Drugs and Herbal Products List. 2019. Available from: https://www.sfda.gov.sa/En/Pages/default.aspx

9. Saudi Press Agency. Saudi Ministry of Health lunches calling center for emergency, 2013 [cited 2020 Apr 14]. Available from: https://www.spa.gov.sa/1109571

10. Grewal A, Kataria $H$, Dhawan I. Literature search for research planning and identification of research problem. Indian J Anaesth 2016; 60(9): 635-639.

11. Braun V, Clarke V. What can "thematic analysis" offer health and wellbeing researchers? Int J Qual Stud Health Well-being 2014; 9: 26152.

12. DRUGDEX® System. Azithromycin and Hydroxychloroquine. Thomson Micromedex, 2020 [cited 2019 Dec 13]. Available from: www.micromedexsolutions.com

13. Benn K, Salman S, Page-Sharp M, Davis TME, Buttery JP. Bradycardia and Hypothermia Complicating Azithromycin Treatment. Am J Case Rep 2017; 18: 883-886.

14. Shipman WD, Vernice NA, Demetres M, Jorizzo JL. An update on the use of hydroxychloroquine in cutaneous lupus erythematosus: A systematic review. J Am Acad Dermatol 2020; 82(3): 709-722.

15. Sarkar M, Woodland $C$, Koren G, Einarson ARN. Pregnancy outcome following gestational exposure to azithromycin. BMC Pregnancy Childbirth 2006; 6(18): 15.

16. Eudy AM, Siega-Riz AM, Engel SM, Franceschini $N$, Howard AG, Clowse MEB, Petri M. Effect of pregnancy on disease flares in patients with systemic lupus erythematosus. Ann Rheum Dis 2018; 77(6): 855-860.

17. Flint J, Panchal S, Hurrell A, van de Venne M, Gayed M, Schreiber $K$, Arthanari S, Cunningham J, Flanders L, Moore L, et al. BSR and BHPR Standards G and AWG. $B S R$ and BHPR guideline on prescribing drugs in pregnancy and breastfeeding-Part $I$ : standard and biologic disease modifying anti-rheumatic drugs and corticosteroids. Rheumatology (Oxford) 2016; 55(9): 1693-1697.

18. Al-Herz A, Schulzer M, Esdaile JM. Survey of antimalarial use in lupus pregnancy and lactation. I Rheumatol 2002; 29(4): 700-706. 